\title{
Psychosomatic complaints profile in patients with type 2 diabetes: a matched case-control study
}

\author{
Zahra Heidari ${ }^{1}$, Awat Feizi ${ }^{1,2,4^{*}}$ (D), Ammar Hassanzadeh Keshteli ${ }^{3,4}$, Hamid Afshar ${ }^{2}$, Hamidreza Roohafza ${ }^{2,5}$ and \\ Peyman Adibi ${ }^{4,6}$
}

\begin{abstract}
Objective: To compare the prevalence of psychosomatic symptoms and their mean scores of profiles in diabetic patients and sample of sex-age-matched healthy controls.

Methods: This case-control study was conducted on 87 patients with type 2 diabetes. The control group consisted of 259 age- and gender-matched healthy participants. Psychosomatic symptoms were assessed using a comprehensive 31-item questionnaire, and psychological problems were evaluated by 12-item General Health Questionnaire and Hospital Anxiety and Depression Scale. Factor analysis, independent Student's $t$ test, analysis of variance, and chi-square test were used for analyzing of data.

Results: The frequency of 18 psychosomatic symptoms was significantly higher in diabetic patients with psychological problems compared with controls $(P<0.05)$, and the most frequent were "severe fatigue" (54.3\%), "feeling low on energy" (48.6\%), "disturbing thoughts" (45.7\%), "pain in the joints" (34.3\%), and "eyesore" (32.4\%). There were significant differences in terms of "psycho-fatigue" ( $P \leq 0.0001)$, "gastrointestinal" $(P=0.018)$, "neuroskeletal" ( $P=0.001)$, and "pharyngeal-respiratory" $(P=0.009)$ profiles between studied groups.

Conclusions: In conclusion, diabetic patients with psychological problems had a higher frequency of psychosomatic symptoms and also higher scores of psychosomatic disorder profiles than control participants. However, further prospective investigations are required to assess whether the psychosomatic disorder/symptom pattern was caused by conditions of diabetes disease.
\end{abstract}

Keywords: Diabetes, Psychological problems, Psychosomatic disorders

\section{Introduction}

Diabetes mellitus is an important cause of global morbidity and mortality rates due to complications such as stroke, ischemic heart disease, and diabetic retinopathy, and its prevalence is increasing, particularly in developing countries [1, 2]. The World Health Organization (WHO) and International Diabetes Federation (IDF) estimated a global prevalence of 422 million people with diabetes in 2014, which is expected to increase to 642

\footnotetext{
* Correspondence: awat_feiz@hlth.mui.ac.ir

${ }^{1}$ Department of Biostatistics and Epidemiology, School of Health, Isfahan University of Medical Sciences, P.O. Box 319, Hezar-Jerib Ave, Isfahan 81746-73461, Iran

${ }^{2}$ Psychosomatic Research Center, Isfahan University of Medical Sciences, Isfahan 81746-73461, Iran

Full list of author information is available at the end of the article
}

million by 2040 [3, 4]. The national prevalence of diabetes in Iran is estimated to be $11.4 \%$, showing a $35 \%$ increase from 2005 to 2011 [5]. Approximately 30\% of diabetic patients in Iran are not aware of their disease; therefore, more attention should be paid to diabetes-related complications in Iranian patients [6, 7].

Diabetes is associated with numerous comorbidities, including obesity, hypertension, and psychological problems [8]. Previous evidences suggested that psychological problems are common among diabetic patients, and they are at substantial risk of enhanced depression, anxiety, and stress. It is reported that depressive symptoms are two times more common in patients with diabetes; in addition, they are more susceptible to anxiety symptoms, anxiety disorders, stress reactivity, and psychological 
distress than population without diabetes [9-12]. The detrimental effects of these comorbidities in people with diabetes can be seen in a reduced quality of life, an increased risk for micro- and macro-vascular complications, poorer self-care behavior, and early mortality [13].

Psychosomatic or somatoform symptoms, which are defined as the presence of physical bodily complaints not fully explained by organic reasons, are common to both medical disorders and psychological problems [14, 15]. These symptoms, such as fatigue, dizziness and confusion, feeling faint, nausea, dry mouth, and appetite disturbances can all be attributable to diabetes [16], which can further reduce the quality of life of these patients. Despite several studies that reported high levels of psychological problems among diabetic patients [9-11, 17, 18], but rare studies have examined the frequency of psychosomatic symptoms among diabetic patients $[16,19]$.

This study was conducted to report the prevalence of psychosomatic symptoms and their profiles in diabetic patients with psychological problems and diabetic patients without psychological problems, in comparison with a group of sex-age-matched healthy controls. We postulated that these psychosomatic symptoms would occur more frequently among diabetic patients than normal population.

\section{Materials and methods}

\section{Study design and participants}

This case-control study was derived from a larger population-based study called "Study of the Epidemiology of Psychological, Alimentary Health and Nutrition" (SEPAHAN) project, which was conducted among a large sample of Iranian adult population in the Isfahan province. Data collection in the SEPAHAN study was performed in two phases. In the first step, different questionnaires that contained information on demographic, lifestyle, and dietary data were sent to 10,087 invited persons, and 8691 subjects returned the completed questionnaire (response rate $86.16 \%$ ). At the second phase, information on gastrointestinal, psychological, and somatoform symptoms was recruited and 6239 returned the completed questionnaires (response rate 64.64\%). Then, national identification numbers of the participants were used to link the questionnaires from both phases. In total, 87 patients with type 2 diabetes participated in the SEPAHAN project. The control sample of this study consisted of the other SEPAHAN participants, and they were paired (one-to-one) by sex and age with the type 2 diabetic patients. The control group included a total of 259 participants (three times the case group). A signed written informed consent form was obtained from all participants. The study protocol was approved by the Ethics Committee of Isfahan University of Medical Sciences, and was registered in the Iranian clinical trials website (www.irct.ir) with the registration number IR.MUI.MED.REC.1398.188. Other details about the SEPAHAN project are fully described elsewhere [20].

\section{Procedures and assessment of variables Assessment of psychosomatic/somatoform symptoms}

In the SEPAHAN project, a separate questionnaire was not available to assess psychosomatic symptoms; however, we found common items among questions contained in SEPAHAN's questionnaires with "the patient health questionnaire (PHQ)" [21] and "the 47-item questionnaire used in the Lacourt et al.'s study" [22] (as valid and standard tools for the assessment of psychosomatic symptoms), and established a validated questionnaire. This questionnaire includes 31 items divided into 4 domains (psychological (6 items), gastrointestinal (10 items), neuro-skeletal (9 items), and pharyngeal-respiratory (6 items)) [23]. It was used to evaluate the frequency of each psychosomatic symptom in the past 3 months experienced by study participants. Each item is based on a 4-point Likert scale (never, sometimes, often, and always). For the "dry mouth" item, the rating scale was as "never, low, and high." Content validity of this questionnaire was measured by evaluating the relevance of each item by a team of gastroenterologists, internists, and psychiatrists. We performed a separate mini survey on 100 randomly selected participants in order to assess the reliability of this questionnaire. There was a strong internal reliability based on Cronbach's alpha score of 0.903 [23].

\section{Assessment of psychological variables}

Psychological distress The Iranian-validated General Health Questionnaire (GHQ) with 12 items was used to detect psychological distress [24]. Each item, including participants' recent particular symptoms or behavior, is based on a 4-point Likert scale (less than usual, no more than usual, rather more than usual, or much more than usual). According to a bimodal scoring style (0-0-1-1), this instrument gives scores ranging from 0 to 12 to each participant. Higher scores (4 or more) indicate a high level of psychological distress. The internal consistency was assessed by Cronbach's alpha coefficient, and it was found to be 0.87 [24].

Hospital Anxiety and Depression Scale The Hospital Anxiety and Depression Scale (HADS) validated for Iranians was used to measure depression and anxiety of participants [25]. HADS is a self-administered questionnaire that consists of 14 items, seven for anxiety (HADS-A) and seven for depression (HADS-D). It has a 4-point scale ranging from 0 (not present) to 3 (considerable). The participant score could be between 0 and 21 
points (0-7 "healthy," 8-10 "borderline," and $\geq 11$ "severe") for each condition. Internal consistency which is assessed by Cronbach's alpha has been found to be 0.78 [25].

\section{Assessment of other variables}

Information about age (year), gender, marital status (single/married), educational level (under diploma, diploma (12-year formal education), and university graduate), smoking status (non-smoker, former smoker, and current smoker), and lifestyle characteristics (weight $(\mathrm{kg})$, height $(\mathrm{m})$, physical activity (inactive and moderately inactive/moderately active and active) based on the General Practice Physical Activity Questionnaire (GPPAQ) [26]) was gathered using a self-administered standard questionnaire. Body mass index (BMI) was computed as weight in kilogram divided by height in meters squared.

\section{Statistical analysis}

Profiles of psychosomatic symptoms were extracted using exploratory factor analysis (based on the principal component extraction approach and orthogonal varimax rotation procedure). Four psychosomatic symptom profiles (i.e., "psycho-fatigue," "gastrointestinal," "neuroskeletal," and "pharyngeal-respiratory") were labeled based on the loaded psychosomatic symptoms in each factor. The factor scores for each profile were computed by summing up items of psychosomatic symptoms weighted by their factor loadings and assigned to each participant. More details about the results of factor analysis on psychosomatic symptoms are presented elsewhere $[14,23]$. In this study, quantitative and qualitative variables were expressed as mean (SD) and frequency (percentage), respectively. We stratified participants into three groups: "controls," "diabetic patients without psychological problems," and "diabetic patients with psychological problems." Patients with psychological problems were defined as having at least one of three common psychological problems, i.e., depression, anxiety, and psychological distress. Independent Student's $t$ test and analysis of variance (ANOVA) were used to compare quantitative variables between case and control groups. Distribution of categorical variables was compared between study groups using the chi-square test. Data analyses were performed using IBM SPSS statistical software (version 21; IBM Corporation, Armonk, NY).

\section{Results}

Three hundred and forty-six persons participated in this study, including 87 with type 2 diabetes and 259 without (controls). The groups were homogenously distributed $(P>0.05)$ regarding age, sex, educational level, marital status, physical activity, smoking status, psychological distress, and depression, as shown in Table 1. However, patients with type 2 diabetes had higher BMI $(P=0.004)$ and anxiety $(P=0.017)$ scores than controls (Table 1$)$.

The prevalence of the psychosomatic symptoms among patients with type 2 diabetes and controls is presented in Table 2. As can be seen, we separated diabetic patients without psychological problems from patients with psychological problems. Diabetic patients with psychological problems reported 18 psychosomatic symptoms significantly higher than controls $(P<0.05)$, including sleep disorder, pounding heart, feeling low on energy, feeling like "butterflies" in the stomach, difficulty concentrating, disturbing thoughts, dry mouth, chest pain, pain or discomfort in the abdomen, pain in the joints, eyesore, severe fatigue, dizziness and confusion, chills and extreme cold, hot flashes, globus sensation, shortness of breath, and wheezing (asthma). In the "often/always" level, the commonest psychosomatic symptoms reported among diabetic patients with psychological problems were "severe fatigue" (54.3\%), "feeling low on energy" (48.6\%), and "disturbing thoughts" (45.7\%), followed by "pain in the joints" (34.3\%) and "eyesore" (32.4\%). In the "sometimes" level, the commonest psychosomatic symptoms reported among diabetic patients with psychological problems were headaches (57.6\%) and sleep disorder (54.3\%), followed by chest pain $(52.9 \%)$ and difficulty concentrating (51.4\%). There were significant differences between diabetic patients without psychological problems and controls in terms of dry mouth and bloating or swelling of the abdomen $(P<0.05)$ (Table 2).

Four extracted profiles using exploratory factor analysis on psychosomatic symptoms were labeled as psycho-fatigue, gastrointestinal, neuro-skeletal, and pharyngeal-respiratory, which accounted for $12.4 \%$, $12.3 \%, 11.4 \%$, and $9.3 \%$ of the total variance, respectively (Table 3) [14].

Table 4 presents the mean scores of four psychosomatic symptom profiles in diabetic patients and controls. As can be seen, the mean (SD) of psycho-fatigue (10.32 (3.39) vs. 9.33 (3.04), $P=0.015)$, gastrointestinal (13.10 (3.41) vs. 12.30 (2.95), $P=0.072$ ), neuro-skeletal (15.68 (4.44) vs. 14.84 (4.13), $P=0.142)$, and pharyngealrespiratory $(9.32(1.89)$ vs. $8.72(1.98), P=0.009)$ profiles was higher in diabetic patients compared to controls.

According to Table 4, there were significant differences in terms of psycho-fatigue $(P \leq 0.0001)$, gastrointestinal $(P=0.018)$, neuro-skeletal $(P=0.001)$, and pharyngealrespiratory $(P=0.009)$ profiles between the three studied groups (diabetic patients with psychological problems, diabetic patients without psychological problems, and controls). Based on the Bonferroni post hoc test, as can be seen, the mean of all psychosomatic symptom profiles was higher in diabetic patients suffering from each 
Table 1 Demographic, lifestyle, and psychological characteristics of study participants

\begin{tabular}{|c|c|c|c|}
\hline Characteristics & Control $(n=259)$ & Diabetes $(n=87)$ & $P$ value \\
\hline Age & $46.94(3.96)$ & $45.74(7.24)$ & 0.17 \\
\hline \multicolumn{4}{|l|}{ Gender } \\
\hline Male & $152(58.7)$ & $57(65.5)$ & \multirow[t]{2}{*}{0.26} \\
\hline Female & $107(41.3)$ & $30(34.5)$ & \\
\hline \multicolumn{4}{|l|}{ Education level } \\
\hline Under diploma & $48(19.2)$ & $21(24.7)$ & \multirow[t]{3}{*}{0.14} \\
\hline Diploma & $70(28.0)$ & $27(31.8)$ & \\
\hline Collegiate & $132(52.8)$ & $37(43.5)$ & \\
\hline \multicolumn{4}{|l|}{ Marital status } \\
\hline Married & $228(90.5)$ & $80(95.2)$ & \multirow[t]{2}{*}{0.17} \\
\hline Single & $24(9.5)$ & $4(4.8)$ & \\
\hline BMl & $26.06(3.61)$ & $27.48(4.45)$ & 0.004 \\
\hline \multicolumn{4}{|l|}{ Physical activity } \\
\hline Inactive and moderately inactive & $138(58.2)$ & $54(67.5)$ & \multirow[t]{2}{*}{0.14} \\
\hline Moderately active and active & $99(41.8)$ & $26(32.5)$ & \\
\hline \multicolumn{4}{|l|}{ Smoking status } \\
\hline Non-smoker & $178(80.5)$ & $61(82.4)$ & \multirow[t]{3}{*}{0.37} \\
\hline Former smoker & $26(11.8)$ & $5(6.8)$ & \\
\hline Current smoker & $17(7.7)$ & $8(10.8)$ & \\
\hline \multicolumn{4}{|l|}{ Psychological distress } \\
\hline No & $196(80.7)$ & $59(74.7)$ & \multirow[t]{2}{*}{0.26} \\
\hline Yes & $47(19.3)$ & $20(25.3)$ & \\
\hline \multicolumn{4}{|l|}{ Anxiety } \\
\hline No & $223(90.7)$ & $68(82.9)$ & \multirow[t]{2}{*}{0.056} \\
\hline Yes & $23(9.3)$ & $14(17.1)$ & \\
\hline \multicolumn{4}{|l|}{ Depression } \\
\hline No & $179(72.8)$ & $53(65.4)$ & \multirow[t]{2}{*}{0.21} \\
\hline Yes & $67(27.2)$ & $28(34.6)$ & \\
\hline GHQ score & $1.98(2.55)$ & $2.13(2.56)$ & 0.63 \\
\hline Anxiety score & $2.85(3.11)$ & 4.04 (3.92) & 0.017 \\
\hline Depression score & $6.01(3.25)$ & $6.44(3.38)$ & 0.23 \\
\hline
\end{tabular}

Values are mean (SD) or frequency (percentage). $P$ values are based on independent Student's $t$ test or chi-square test as appropriate

psychological problem than in the control group (Table 4). The mean scores of the neuro-skeletal profile in diabetic patients with anxiety and/or depression were significantly higher than those in patients without the problems $(P<0.01)$. In addition, as it was expected, the mean scores of the psycho-fatigue profile in diabetic patients with anxiety, depression, and/or psychological distress were significantly higher than those in patients without the problems $(P<0.01)$. However, there is no significant difference in terms of the gastrointestinal profile between diabetic patients with psychological distress, diabetic patients without psychological distress, and controls $(P=0.175$; Table 4$)$.

\section{Discussion}

This case-control study among patients with type 2 diabetes and a control group of participants without diabetes demonstrated that diabetic patients particularly those with psychological problems had a significantly higher prevalence of psychosomatic symptoms and total score of psychosomatic symptom profiles than controls. We found that the scores of psychofatigue, gastrointestinal, neuro-skeletal, and pharyngeal-respiratory profiles among diabetic patients with psychological problems were significantly higher than those among the control group and among diabetic patients without psychological 
Table 2 Prevalence of psychosomatic symptoms in diabetic patients and controls

\begin{tabular}{|c|c|c|c|c|c|c|c|c|}
\hline \multirow[t]{2}{*}{ Psychosomatic symptoms } & \multicolumn{2}{|c|}{ Controls $(n=259)$} & \multicolumn{2}{|c|}{$\begin{array}{l}\text { Diabetic patients without } \\
\text { psychological problems }(n= \\
\text { 52) }\end{array}$} & \multirow[t]{2}{*}{$P$ value } & \multicolumn{2}{|c|}{$\begin{array}{l}\text { Diabetic patients with } \\
\text { psychological problems }(n= \\
\text { 35) }\end{array}$} & \multirow[t]{2}{*}{$P$ value } \\
\hline & Sometimes & Often/always & Sometimes & Often/always & & Sometimes & Often/always & \\
\hline Sleep disorder & $67(27.9)$ & $43(17.9)$ & $12(27.3)$ & $3(6.8)$ & 0.064 & $19(54.3)$ & $9(25.7)$ & 0.003 \\
\hline Pounding heart & $88(35.1)$ & $18(7.2)$ & $13(26.0)$ & $3(6.0)$ & 0.24 & $16(45.7)$ & $7(20.0)$ & 0.002 \\
\hline Feeling low on energy & $112(45.5)$ & $43(17.5)$ & $27(57.4)$ & $3(6.4)$ & 0.35 & $17(48.6)$ & $17(48.6)$ & $<0.0001$ \\
\hline Feeling like "butterflies" in the stomach & $57(23.4)$ & $7(2.9)$ & $10(21.3)$ & $0(0.0)$ & 0.33 & $15(44.1)$ & $7(20.6)$ & $<0.0001$ \\
\hline Difficulty concentrating & $64(26.1)$ & $13(5.3)$ & $9(18.8)$ & $0(0.0)$ & 0.042 & $18(51.4)$ & $7(20.0)$ & $<0.0001$ \\
\hline Disturbing thoughts & $90(36.7)$ & $26(10.6)$ & $19(40.4)$ & $2(4.3)$ & 0.39 & $12(34.3)$ & $16(45.7)$ & $<0.0001$ \\
\hline Dry mouth* & $85(33.9)$ & $4(1.6)$ & $24(48.0)$ & $10(20.0)$ & $<0.0001$ & $15(45.5)$ & $9(27.3)$ & $<0.0001$ \\
\hline Chest pain & $80(32.5)$ & $11(4.5)$ & $16(32.0)$ & $2(4.0)$ & 0.87 & $18(52.9)$ & $4(11.8)$ & 0.001 \\
\hline Feeling of fullness & $82(32.4)$ & $18(7.1)$ & $19(38.0)$ & $0(0.0)$ & 0.36 & $12(34.3)$ & $6(17.1)$ & 0.06 \\
\hline Nausea & $24(9.7)$ & $4(1.6)$ & $4(8.0)$ & $0(0.0)$ & 0.9 & $6(17.1)$ & $1(2.9)$ & 0.24 \\
\hline Gastroesophageal reflux & $49(20.2)$ & $2(0.8)$ & $14(26.9)$ & $0(0.0)$ & 0.56 & $6(17.6)$ & $2(5.9)$ & 0.12 \\
\hline Pain or discomfort in the abdomen & $84(34.1)$ & $12(4.9)$ & 19 (38.8) & $2(4.1)$ & 0.74 & $15(42.9)$ & $4(11.4)$ & 0.045 \\
\hline Constipation & 98 (38.6) & $23(9.1)$ & $22(44.0)$ & $3(6.0)$ & 0.95 & $14(40.0)$ & $6(17.1)$ & 0.14 \\
\hline Diarrhea & $72(28.8)$ & $5(2.0)$ & $19(38.0)$ & $0(0.0)$ & 0.38 & $11(33.3)$ & $0(0.0)$ & 0.83 \\
\hline Bloating or swelling of the abdomen & $103(42.2)$ & $33(13.5)$ & $15(30.0)$ & $4(8.0)$ & 0.031 & $17(50.0)$ & $6(17.6)$ & 0.21 \\
\hline Anal pain & $45(18.9)$ & $3(1.3)$ & $8(17.4)$ & $2(4.3)$ & 0.33 & $8(22.9)$ & $1(2.9)$ & 0.45 \\
\hline Headache & $137(54.6)$ & $38(15.1)$ & $29(60.4)$ & $3(6.3)$ & 0.24 & $19(57.6)$ & $6(18.2)$ & 0.46 \\
\hline Back pain & $112(45.2)$ & $47(19.0)$ & $22(44.0)$ & $11(22.0)$ & 0.66 & $14(42.4)$ & $10(30.3)$ & 0.14 \\
\hline Pain in the joints & $115(45.6)$ & $44(17.5)$ & $28(56.0)$ & $6(12.0)$ & 0.59 & $17(48.6)$ & $12(34.3)$ & 0.005 \\
\hline Eyesore & $89(35.0)$ & $18(7.1)$ & $18(36.0)$ & $5(10.0)$ & 0.48 & $7(20.6)$ & $11(32.4)$ & 0.003 \\
\hline Severe fatigue & $138(54.8)$ & $66(26.2)$ & $29(59.2)$ & $10(20.4)$ & 0.49 & $16(45.7)$ & $19(54.3)$ & $<0.0001$ \\
\hline Dizziness and confusion & $80(31.9)$ & $17(6.8)$ & 19 (38.8) & $0(0.0)$ & 0.48 & $13(37.1)$ & $6(17.1)$ & 0.025 \\
\hline Chills and extreme cold & $54(21.3)$ & $3(1.2)$ & $6(12.2)$ & $1(2.0)$ & 0.25 & $13(39.4)$ & $1(3.0)$ & 0.033 \\
\hline Hot flashes & $66(26.5)$ & $16(6.4)$ & $17(34.7)$ & $2(4.1)$ & 0.71 & $11(32.4)$ & $9(26.5)$ & $<0.0001$ \\
\hline Neck pain & $54(21.4)$ & $7(2.8)$ & $14(28.0)$ & $0(0.0)$ & 0.89 & $12(36.4)$ & $1(3.0)$ & 0.103 \\
\hline Globus sensation & $36(14.3)$ & $4(1.6)$ & $7(14.0)$ & $1(2.0)$ & $>0.999$ & $12(35.3)$ & $0(0.0)$ & 0.014 \\
\hline Having trouble swallowing & $17(6.7)$ & $1(0.4)$ & $2(4.1)$ & $0(0.0)$ & 0.79 & $4(11.8)$ & $0(0.0)$ & 0.37 \\
\hline Shortness of breath & $79(32.0)$ & $13(5.3)$ & $19(38.0)$ & $1(2.0)$ & 0.95 & $13(39.4)$ & $5(15.2)$ & 0.017 \\
\hline Hoarseness & $39(15.7)$ & $5(2.0)$ & $7(14.3)$ & $1(2.0)$ & 0.84 & $6(17.6)$ & $1(2.9)$ & 0.65 \\
\hline Wheezing (asthma) & $18(7.2)$ & $10(4.0)$ & $3(6.0)$ & $4(8.0)$ & 0.43 & $9(26.5)$ & $1(2.9)$ & 0.004 \\
\hline
\end{tabular}

Values are number (\%). $P$ value from Pearson $x^{2}$

*The rating scale was as never, low, and high

problems. In addition, the results showed that gastrointestinal and neuro-skeletal symptoms among diabetic patients with anxiety were more prominent.

The majority of previous studies were restricted to the investigation of the prevalence of psychological problems among diabetic patients [27-31]. A few studies have examined the distribution of psychosomatic symptoms among diabetic patients, which include a few psychosomatic symptoms or an overall score of somatization $[16,19]$. In the present study, not only the most important psychosomatic symptoms in groups with and without diabetes were compared, but also the distribution of distinct profiles of psychosomatic symptoms (extracted from factor analysis) among diabetic patients with and without psychological problems and controls was compared.

In the current study, "headache, severe fatigue, feeling low on energy, pain in the joints, and dry mouth" were the commonest psychosomatic symptoms reported among diabetic patients without psychological problems; however, there were significant differences between diabetic patients without psychological problems and controls only in terms of dry mouth. In Aikens' study, "anenergia, memory problems, overeating, numbness, reduced libido, weakness, and 
Table 3 Factor loadings for the four extracted psychosomatic disorder profiles from psychosomatic symptoms

\begin{tabular}{|c|c|c|c|c|}
\hline \multirow[t]{2}{*}{ Psychosomatic symptoms } & \multicolumn{4}{|l|}{ Factor loadings* } \\
\hline & Psycho-fatigue & Gastrointestinal & Neuro-skeletal & Pharyngeal-respiratory \\
\hline Sleep disorder & 0.46 & & & \\
\hline Pounding heart & 0.41 & & 0.41 & \\
\hline Feeling low on energy & 0.69 & & & \\
\hline Feeling like "butterflies" & 0.78 & & & \\
\hline Difficulty concentrating & 0.64 & & & \\
\hline Disturbing thoughts & 0.80 & & & \\
\hline Chest pain & & 0.52 & & \\
\hline Feeling of fullness & & 0.69 & & \\
\hline Nausea & & 0.50 & & \\
\hline Gastroesophageal reflux & & 0.54 & & \\
\hline Pain or discomfort in the abdomen & & 0.71 & & \\
\hline Constipation & & 0.49 & & \\
\hline Diarrhea & & 0.36 & & \\
\hline Bloating or swelling of the abdomen & & 0.67 & & \\
\hline Anal pain & & 0.48 & & \\
\hline Headache & & & 0.57 & \\
\hline Back pain & & & 0.66 & \\
\hline Pain in the joints & & & 0.64 & \\
\hline Eyesore & & & 0.50 & \\
\hline Severe fatigue & & & 0.61 & \\
\hline Dizziness and confusion & & & 0.51 & \\
\hline Chills and extreme cold & & & 0.42 & \\
\hline Hot flashes & & & 0.38 & \\
\hline Dry mouth & & & & 0.31 \\
\hline Neck pain & & & & 0.56 \\
\hline Globus sensation & & & & 0.55 \\
\hline Having trouble swallowing & & & & 0.61 \\
\hline Shortness of breath & & & & 0.46 \\
\hline Hoarseness & & & & 0.61 \\
\hline Wheezing (asthma) & & & & 0.52 \\
\hline Variance explained (\%) & 12.4 & 12.3 & 11.4 & 9.3 \\
\hline Cumulative variance & 12.4 & 24.7 & 36.1 & 45.4 \\
\hline
\end{tabular}

*Factor loadings $<0.3$ are not shown for simplicity

faintness/dizziness" were more frequently of somatic complaints reported by diabetic patients [16]. According to our results, diabetic patients with psychological problems reported several psychosomatic symptoms significantly higher than controls, and severe fatigue, feeling low on energy, disturbing thoughts, pain in the joints, and eyesore were more frequently reported among them. In this regard, there are evidences suggesting that the experience of high psychosomatic disorder/symptom burden is strongly associated with adverse mental health conditions such as anxiety, depression, or low self-perceived health [19, 32, 33].
Our study showed significantly higher scores of psycho-fatigue and pharyngeal-respiratory profiles in patients with diabetes than in controls, and also, diabetic patients with psychological problems had higher scores of two aforesaid profiles. In the current study, the psycho-fatigue profile is characterized by sleep disorder, pounding heart, feeling low on energy, feeling like "butterflies," difficulty concentrating, and disturbing thoughts symptoms and the pharyngeal-respiratory profile characterized by dry mouth, neck pain, globus sensation, having trouble swallowing, shortness of breath, 
Table 4 Mean scores of psychosomatic symptom profiles in studied groups

\begin{tabular}{|c|c|c|c|c|}
\hline & \multicolumn{4}{|c|}{ Psychosomatic symptom profiles } \\
\hline & Psycho-fatigue & Gastrointestinal & Neuro-skeletal & Pharyngeal-respiratory \\
\hline Diabetic patients $(n=87)$ & $10.32(3.39)$ & $13.10(3.41)$ & $15.68(4.44)$ & $9.32(1.89)$ \\
\hline Control $(n=259)$ & $9.33(3.04)$ & $12.30(2.95)$ & $14.84(4.13)$ & $8.72(1.98)$ \\
\hline$P$ value & 0.015 & 0.072 & 0.142 & 0.009 \\
\hline (a) Diabetic patients with psychological problems $(n=35)$ & $12.82(3.27)^{* * * *}$ & $14.00(3.57)^{*}$ & $17.93(4.85)^{* * * *}$ & $9.73(1.87)^{*}$ \\
\hline (b) Diabetic patients without psychological problems $(n=52)$ & $8.39(1.88)$ & $12.38(3.14)$ & $14.20(3.47)$ & $9.04(1.87)$ \\
\hline (c) Control $(n=259)$ & $9.33(3.04)$ & $12.29(2.95)$ & $14.84(4.13)$ & $8.72(1.98)$ \\
\hline$P$ value & $<0.0001$ & 0.018 & 0.001 & 0.009 \\
\hline (a) Diabetic patients with psychological distress $(n=20)$ & $13.45(3.41)^{* * * *}$ & $13.33(3.20)$ & $18.88(5.74)^{* * *}$ & $9.94(2.15) *$ \\
\hline (b) Diabetic patients without psychological distress $(n=67)$ & $9.24(2.64)$ & $13.02(3.50)$ & $14.79(3.58)$ & $9.12(1.78)$ \\
\hline (c) Control $(n=259)$ & $9.33(3.04)$ & $12.29(2.95)$ & $14.84(4.13)$ & $8.72(1.98)$ \\
\hline$P$ value & $<0.0001$ & 0.175 & 0.003 & 0.010 \\
\hline (a) Diabetic patients with anxiety $(n=14)$ & $16.00(2.04)^{* * * *}$ & $16.00(3.83)^{* * * *}$ & $21.50(4.79)^{* * * *}$ & $10.40(1.71)^{*}$ \\
\hline (b) Diabetic patients without anxiety $(n=73)$ & $9.18(2.27)$ & $12.44(2.96)$ & $14.76(3.64)$ & $9.15(1.87)$ \\
\hline (c) Control $(n=259)$ & $9.33(3.04)$ & $12.29(2.95)$ & $14.84(4.13)$ & $8.72(1.98)$ \\
\hline$P$ value & $<0.0001$ & $<0.0001$ & $<0.0001$ & 0.005 \\
\hline (a) Diabetic patients with depression $(n=28)$ & $13.41(3.24)^{* * * *}$ & $14.60(3.58)^{* * * *}$ & $18.43(4.74)^{* * * *}$ & $9.78(1.68)^{*}$ \\
\hline (b) Diabetic patients without depression $(n=59)$ & $8.69(2.08)$ & $12.27(3.04)$ & $14.42(3.70)$ & $9.12(1.96)$ \\
\hline (c) Control $(n=259)$ & $9.33(3.04)$ & $12.29(2.95)$ & $14.84(4.13)$ & $8.72(1.98)$ \\
\hline$P$ value & $<0.0001$ & 0.002 & $<0.0001$ & 0.010 \\
\hline
\end{tabular}

Values are mean (SD). $P$ values are based on ANOVA test

*Significant difference a versus $b$

**Significant difference a versus c

hoarseness, and wheezing (asthma) symptoms. According to the results of the cohort study by Baumert et al., the mean somatic symptom score was higher for the type 2 diabetes group than for non-cases of diabetes [19]. In the aforesaid study, the somatization score was established based on stomach or bowel pain, back pain, pain in the joints, headaches or pressure in the head, temporary shortness of breath, dizziness, feeling tired, and insomnia symptoms [19]. In addition, they showed that the risk for type 2 diabetes increased by a hazard ratio (HR) of 1.03 for a one unit increase of the somatization score [19]. As it was mentioned, previous studies showed that psychological problems are common among diabetic patients [912]. It is believed that high prevalence of psychological symptoms among diabetic patients is related to poor glycemic control, diabetes complications, worsened prognosis, and quality of life [34].

Our results showed significantly higher scores of neuro-skeletal profile (characterized by headache, back pain, pain in the joints, eyesore, severe fatigue, dizziness and confusion, chills and extreme cold, and hot flashes) in diabetic patients with psychological problems (especially among diabetic patients with anxiety and depression) than in controls. It is showed that diabetic patients may develop several musculoskeletal symptoms, because of the severity and duration of the disease, so that these conditions may affect the joints, soft tissues, nerves, muscles, or tendons [35]. It seems that some of these conditions stem from other complications of diabetes, such as peripheral neuropathy, and others seem to be directly caused by the metabolic abnormality, with direct glycosylation damaging tissues [35].

Our study showed significantly higher scores of gastrointestinal profile (characterized by chest pain, feeling of fullness, nausea, gastroesophageal reflux, pain or discomfort in the abdomen, constipation, diarrhea, bloating or swelling of the abdomen, anal pain) in diabetic patients with anxiety and depression than in controls and other diabetic patients. It is reported that gastrointestinal symptoms occur more frequently in both type 1 and type 2 diabetic patients, who exhibit higher levels of psychosocial problems [36, 37]; psychological disorders, including anxiety and depression, are strongly associated with gastrointestinal symptoms [37]. On the other hand, acute changes in blood glucose concentration affect gastrointestinal motor function and increase perceptions of nausea, fullness, and bloating [37, 38]. 


\section{Strengths and limitations}

It is important to recognize some strengths, as well as potential limitations of the present study. A major strength of our study is the investigation of several psychosomatic symptoms as well as their profile scores. Therefore, not only we considered them separately, but also we investigated a composite measure of them. Additionally, as far as we know, this is the first study that investigates the distribution of a wide spectrum of psychosomatic symptoms in diabetic patients compared to controls. Several limitations need to be considered when interpreting our findings. It should be emphasized that all used information in the present analysis were collected by self-administered questionnaires, and this method of data collection might lead to misclassifying the participants. In addition, the psychosomatic symptoms in our study can only be characterized as indicative of somatization. Finally, future studies would benefit from a larger diabetes patient sample, which would provide the more precise results.

\section{Conclusion}

In conclusion, diabetic patients had a higher frequency of psychosomatic symptoms than control participants. Diabetic patients with psychological disorders reported a greater frequency of sleep disorder, chest pain, and difficulty concentrating. Also, we found that the scores of psycho-fatigue, gastrointestinal, neuro-skeletal, and pharyngeal-respiratory profiles among diabetic patients with psychological problems were significantly higher than those among the control group. These findings could be an indication of the key role of psychological problems in diabetes. However, further research is needed to assess whether the psychosomatic disorder/ symptom pattern was caused by conditions of diabetes disease.

\section{Abbreviations \\ BMI: Body mass index; GHQ: General Health Questionnaire; GPPAQ: General Practice Physical Activity Questionnaire; HADS: Hospital Anxiety and Depression Scale; IDF: International Diabetes Federation; PHQ: Patient health questionnaire; SEPAHAN: Study of the Epidemiology of Psychological, Alimentary Health and Nutrition; WHO: World Health Organization}

\section{Acknowledgements}

We are grateful to thank all staff of the Isfahan University of Medical Sciences (MUI) who kindly participated in our study, staff of Public Relations Unit, and other authorities of IUMS for their excellent cooperation.

\section{Authors' contributions}

PA, AHK, HA, and HRR contributed to the SEPAHAN study concepts and design, data collection, and drafting of the manuscript. ZH performed the statistical analysis. ZH and AF drafted the manuscript. AF supervised the current secondary study. All authors read and approved the final version of the manuscript.

\section{Authors' information}

ORCID number: Zahra Heidari (https://orcid.org/0000-0001-7825-2388), Awat Feizi (https://orcid.org/0000-0002-1930-0340), Ammar Hassanzadeh Keshteli (https://orcid.org/0000-0001-7375-6210), Hamid Afshar (https://orcid.org/
0000-0001-7787-8725), Hamidreza Roohafza (https://orcid.org/0000-0003-35 82-0431), Peyman Adibi (https://orcid.org/0000-0003-3247-4828)

\section{Funding}

SEPAHAN was financially supported by a grant from the Vice Chancellery for Research and Technology, Isfahan University of Medical Sciences (IUMS), and it was registered under 3 subprojects with project numbers: \#189069,

$\# 189082$, and \#189086 based on financial regulations of our university.

\section{Availability of data and materials}

The data supporting the results of this article are included within the article.

\section{Ethics approval and consent to participate}

A signed written informed consent form was obtained from all participants. The study protocol was approved by the Ethics Committee of Isfahan University of Medical Sciences, and was registered in the Iranian clinical trials website (www.irct.ir) with the registration number IR.MUI.MED.REC.1398.188.

\section{Consent for publication}

Not applicable.

\section{Competing interests}

The authors declare that they have no competing interests.

\section{Author details}

${ }^{1}$ Department of Biostatistics and Epidemiology, School of Health, Isfahan University of Medical Sciences, P.O. Box 319, Hezar-Jerib Ave, Isfahan 81746-73461, Iran. ${ }^{2}$ Psychosomatic Research Center, Isfahan University of Medical Sciences, Isfahan 81746-73461, Iran. ${ }^{3}$ Department of Medicine, University of Alberta, Edmonton, AB, Canada. ${ }^{4}$ Integrative Functional Gastroenterology Research Centre, Isfahan University of Medical Sciences, Isfahan 81746-73461, Iran. ${ }^{5}$ Cardiac Rehabilitation Research Center, Cardiovascular Research Institute, Isfahan University of Medical Sciences, Isfahan 81746-73461, Iran. ${ }^{6}$ Department of Internal Medicine, School of Medicine, Isfahan University of Medical Sciences, Isfahan 81746-73461, Iran.

Received: 24 January 2019 Accepted: 7 July 2019

Published online: 29 July 2019

\section{References}

1. Ko B, Lim J, Kim YZ, Park HS. Trends in type 2 diabetes prevalence according to income levels in Korea (1998-2012). Diabetes Res Clin Pract. 2016;115:137-9 https://doi.org/10.1016/j.diabres.2016.01.014.

2. Khorrami Z, Yarahmadi S, Etemad K, Khodakarim S, Kameli ME, Mahdavi Hazaveh AR. Urban-rural differences in the prevalence of self-reported diabetes and its risk factors: the WHO STEPS Iranian noncommunicable disease risk factor surveillance in 2011. Iran J Med Sci. 2017:42(5):481-7.

3. World Health Organization. Diabetes. 2017. http://www.who.int/ mediacentre/factsheets/fs312/en/.

4. Ogurtsova K, da Rocha Fernandes JD, Huang Y, Linnenkamp U, Guariguata L, Cho NH, et al. IDF Diabetes Atlas: global estimates for the prevalence of diabetes for 2015 and 2040. Diabetes Res Clin Pract. 2017;128:40-50 https:// doi.org/10.1016/j.diabres.2017.03.024.

5. Esteghamati A, Larijani B, Aghajani MH, Ghaemi F, Kermanchi J, Shahrami A, et al. Diabetes in Iran: prospective analysis from first nationwide diabetes report of National Program for Prevention and Control of Diabetes (NPPCD2016). Sci Rep. 2017;7(1):13461 https://doi.org/10.1038/s41598-017-13379-z.

6. Taheri P, Moradinazar M, Mottlagh ME, Najafi F. The prevalence of diabetes mellitus type II among Iranian elderly population and its association with other age-related diseases, 2012. Arch Gerontol Geriatr. 2014;60(3):373-9 https://doi.org/10.1016/j.archger.2014.11.012.

7. Naseri R, Yavari T, Eftekharzadeh A, Khazaie H. Association between sleep duration and nephropathy in patients with type II diabetes mellitus. Int J Diabetes Dev Ctries. 2018;38(4):375-80 https://doi.org/10.1007/s13410-0170603-0.

8. Amini M, Parvaresh E. Prevalence of macro- and microvascular complications among patients with type 2 diabetes in Iran: a systematic review. Diabetes Res Clin Pract. 2009;83(1):18-25 https://doi.org/10.1016/j. diabres.2008.10.010.

9. Atlantis E, Vogelzangs N, Cashman K, Penninx BJ. Common mental disorders associated with 2-year diabetes incidence: the Netherlands Study of 
Depression and Anxiety (NESDA). J Affect Disord. 2012;142:S30-5 https://doi. org/10.1016/S0165-0327(12)70006-X.

10. Qiu S, Sun XH, Liu WY, Kanu JS, Li R, Yu Y, et al. Prevalence and correlates of psychological distress among diabetes mellitus adults in the Jilin province in China: a cross-sectional study. PeerJ. 2017;5:e2869 https://doi.org/10.7717/ peerj.2869.

11. Winchester RJ, Williams JS, Wolfman TE, Egede LE. Depressive symptoms, serious psychological distress, diabetes distress and cardiovascular risk factor control in patients with type 2 diabetes. J Diabetes Complications. 2016; 30(2):312-7 https://doi.org/10.1016/j.jdiacomp.2015.11.010.

12. Indelicato L, Dauriz M, Santi L, Bonora F, Negri C, Cacciatori V, et al. Psychological distress, self-efficacy and glycemic control in type 2 diabetes. Nutr Metab Cardiovasc Dis. 2017;27(4):300-6 https://doi.org/10.1016/j. numecd.2017.01.006.

13. Ehrmann D, Schmitt A, Reimer A, Haak T, Kulzer B, Hermanns N. The affective and somatic side of depression: subtypes of depressive symptoms show diametrically opposed associations with glycemic control in people with type 1 diabetes. Acta Diabetol. 2017;54(8):749-56 https://doi.org/10.1 007/s00592-017-1006-X.

14. Heidari Z, Feizi A, Roohafza H, Hassanzadeh Keshteli A, Adibi P. Somatoform symptoms profiles in relation to psychological disorders - a population classification analysis in a large sample of general adults. Psychiatry Res. 2017;254:173-8 https://doi.org/10.1016/..psychres.2017.04.064.

15. Stewart SM, Simmons A, White PC. Somatic items in the assessment of depressive symptoms in pediatric patients with diabetes. J Behav Med. 2011;34(2):112-9 https://doi.org/10.1007/s10865-010-9289-1.

16. Aikens JE. Prevalence of somatic indicators of distress in diabetes patients: comparison to psychiatric patients and community nonpatients. Int J Psychiatry Med. 1998;28(3):265-72 https://doi.org/10.2190/RJ82-3JKB-YKEM-BNUO.

17. Yu S, Yang H, Guo X, Zheng L, Sun Y. Prevalence of depression among rural residents with diabetes mellitus: a cross-sectional study from northeast China. Int J Environ Res Public Health. 2016;13(6):542 https://doi.org/10.33 90/ijerph13060542.

18. Grigsby AB, Anderson RJ, Freedland KE, Clouse RE, Lustman PJ. Prevalence of anxiety in adults with diabetes a systematic review. J Psychosom Res. 2002;53(6):1053-60.

19. Baumert J, Meisinger C, Lukaschek K, Emeny RT, Rückert IM, Kruse J, et al. A pattern of unspecific somatic symptoms as long-term premonitory signs of type 2 diabetes: findings from the population-based MONICA/ KORA cohort study, 1984-2009. BMC Endocr Disord. 2014;14:1-9 https://doi.org/10.11 86/1472-6823-14-87.

20. Adibi P, Keshteli AH, Esmaillzadeh A, Afshar H, Roohafza H, BagherianSararoudi R, et al. The study on the epidemiology of psychological, alimentary health and nutrition (SEPAHAN): overview of methodology. J Res Med Sci. 2012:17(5):S292-S298.

21. Spitzer RL, Kroenke K, Williams JB. Validation and utility of a self-report version of PRIME-MD: the PHQ primary care study. Primary Care Evaluation of Mental Disorders. Patient Health Questionnaire. JAMA. 1999;282(18):1737-44.

22. Lacourt T, Houtveen J, van Doornen L. "Functional somatic syndromes, one or many?": an answer by cluster analysis. J Psychosom Res. 2013;74(1):6-11 https://doi.org/10.1016/j.jpsychores.2012.09.013.

23. Heidari Z, Keshteli AH, Feizi A, Afshar H, Adibi P. Somatic complaints are significantly associated with chronic uninvestigated dyspepsia and its symptoms: a large cross-sectional population based study. J Neurogastroenterol Motil. 2017;23(1):80-91 https://doi.org/10.5056/jnm16020

24. Montazeri A, Harirchi AM, Shariati M, Garmaroudi G, Ebadi M, Fateh A. The 12-item General Health Questionnaire (GHQ-12): translation and validation study of the Iranian version. Health Qual Life Outcomes. 2003;1:66 https:// doi.org/10.1186/1477-7525-1-66.

25. Montazeri A, Vahdaninia M, Ebrahimi M, Jarvandi S. The Hospital Anxiety and Depression Scale (HADS): translation and validation study of the Iranian version. Health Qual Life Outcomes. 2003;1:14 https://doi.org/10.1186/1477-7525-1-14.

26. National Collaborating Centre for N. The General Practice Physical Activity Questionnaire (GPPAQ) 2008

27. Boden MT. Prevalence of mental disorders and related functioning and treatment engagement among people with diabetes. J Psychosom Res. 2018;106:62-9 https://doi.org/10.1016/j.jpsychores.2018.01.001.

28. Stanković Ž, Jašović-Gašić M, Lečić-Toševski D. Psychological problems in patients with type 2 diabetes: clinical considerations. Vojnosanit Pregl. 2013; 70(12):1138-44.
29. Virtanen M, Ferrie JE, Tabak AG, Akbaraly TN, Vahtera J, Singh-Manoux A, et al. Psychological distress and incidence of type 2 diabetes in high-risk and low-risk populations: the Whitehall II Cohort Study. Diabetes Care. 2014; 37(8):2091-7 https://doi.org/10.2337/dc13-2725.

30. Domingo AK, Asmal L, Seedat S, Esterhuizen TM, Laurence C, Volmink J. Investigating the association between diabetes mellitus, depression and psychological distress in a cohort of South African teachers. South African Med J. 2015;105(12):1057-60 https://doi.org/10.7196/SAMJ.2015.v105i12.9843.

31. Mezuk B, Chen Y, Yu C, Guo Y, Bian Z, Collins R, et al. Depression, anxiety, and prevalent diabetes in the Chinese population: findings from the China Kadoorie Biobank of 0.5million people. J Psychosom Res. 2013;75(6):511-7 https://doi.org/10.1016/j.jpsychores.2013.09.008.

32. Ladwig KH, Marten-Mittag B, Lacruz ME, Henningsen P, Creed F. Screening for multiple somatic complaints in a population-based survey: does excessive symptom reporting capture the concept of somatic symptom disorders?. Findings from the MONICA-KORA Cohort Study. J Psychosom Res. 2010;68(5):427-37 https://doi.org/10.1016/.jpsychores.2010.01.009.

33. Lieb R, Meinlschmidt G, Araya R. Epidemiology of the association between somatoform disorders and anxiety and depressive disorders: an update. Psychosom Med. 2007;69(9):860-3 https://doi.org/10.1097/PSY.0b013e31815b0103.

34. Bener A, Al-hamaq AOAA, Dafeeah EE. High prevalence of depression, anxiety and stress symptoms among diabetes mellitus patients. Open Access Psychiarty J. 2011;5(1):5-12 https://doi.org/10.2174/1874354401105010005.

35. Merashli M, Chowdhury TA, Jawad ASM. Musculoskeletal manifestations of diabetes mellitus. Qjm. 2015;108(11):853-7 https://doi.org/10.1093/qjmed/ hcv106.

36. Bener A, Ghuloum S, Al-Hamaq AO, Dafeeah EE. Association between psychological distress and gastrointestinal symptoms in diabetes mellitus. World J Diabetes. 2012;3(6):123-9 https://doi.org/10.4239/wjd.v3.6.123.

37. Du YT, Rayner CK, Jones KL, Talley NJ. Gastrointestinal symptoms in diabetes: prevalence, assessment, pathogenesis, and management. Diabetes Care. 2018;41(3):627-37 https://doi.org/10.2337/dc17-1536.

38. Rayner CK, Verhagen MAMT, Hebbard GS, Dimatteo AC, Doran SM, Horowitz M. Proximal gastric compliance and perception of distension in type 1 diabetes mellitus: effects of hyperglycemia. Am J Gastroenterol. 2000;95(5): 1175-83 https://doi.org/10.1111/j.1572-0241.2000.02006.x.

\section{Publisher's Note}

Springer Nature remains neutral with regard to jurisdictional claims in published maps and institutional affiliations.

\section{Submit your manuscript to a SpringerOpen ${ }^{\circ}$ journal and benefit from:}

- Convenient online submission

- Rigorous peer review

- Open access: articles freely available online

- High visibility within the field

- Retaining the copyright to your article

Submit your next manuscript at $\boldsymbol{\nabla}$ springeropen.com 